\title{
Understanding the Formation of Software as a Service (Saas) Commitment
}

\section{the Relational Value Creation Perspective}

\author{
Chia-Shiang Hsu ${ }^{1, *}$, Shih-Wei Chou ${ }^{2}$ \\ ${ }^{1}$ Shu-Te University, Taiwan \\ ${ }^{2}$ National Kaohsiung First University of Science and Technology, Taiwan \\ 1 jacqueshsu@stu.edu.tw*; ${ }^{*}$ swchou@nkfust.edu.tw; \\ * corresponding author
}

(Received: August 9, 2021; Revised: August 21, 2021; Accepted: October 16, 2021; Available online: December 1, 2021)

\begin{abstract}
This study focuses on the use of an important IT innovation--software-as-a-service (SaaS), and draw on sensemaking and the dedication-constraint framework to explain the formation of SaaS commitment. Building on and extending prior studies, we posit that managers' perceived relational value from SaaS consumption transforms their initial sensemaking of SaaS features into commitment. SaaS features are characterized as strength frames and weakness frames. Perceived relational values are conceptualized as process flexibility, task-knowledge coordination, process specificity, and trust. The proposed model and hypotheses are largely supported by the empirical data from 169 SaaS client firms. We discuss theoretical and practical implications.
\end{abstract}

Keywords: Innovation, SaaS, Technological Frames, Dedication-Constraint Framework, Commitment

\section{Introduction}

Despite the potential benefits from SaaS adoption, evidence suggests that SaaS faces uncertainty and the reported failure rate is high. Examples of uncertainty incorporate client firms' low switching costs and perceived risks, SaaS vendors' low customization and control over future SaaS development, process dependence, and information security. Unlike traditional IT-based innovation that focuses on a firm's internal resource management (e.g., process improvement), the extent to which SaaS firms create value relies on their ability to leverage both internal and external resources at the post-adoption stage such as leveraging resources provided by SaaS vendors through good management of the firm vendor relationship (e.g., absorbing SaaS best practices for task improvement) [1]. Few studies focus on SaaS-based innovation at the post-adoption stage that reflects both SaaS features and value creation from the firm-vendor relationship [2]. Because the decision to adopt SaaS is only the first step in a complex process related to absorbing SaaS innovation and maximizing SaaS value relies on good progress beyond the initial adoption stage, it is very critical to examine post-adoption stages of the SaaS-based innovation cycle. Among the measures of post-adoption success that have been used in organizational IT innovation and online service delivery, this study focuses on commitment, defined as one's desire to continue a relationship, willingness to be deeply involved in the relationship through investment, and confidence in the stability in the relationship [3]. This is because commitment reflects a comprehensive evaluation of post-adoption success in terms of resolving challenges from innovation adoption, value creation from investment, and confidence in the involvement in the long-term relationship with the vendor [4]. Therefore, the broad objective of this study is to advance our theoretical understanding of the antecedents of SaaS commitment.

While an increasing number of studies have considered the value creation from the sensemaking and dedication-constraint perspectives separately, they are limited in providing an integrated view and capturing the unique features of SaaS value creation and how it affects post-adoption behavior [5]. There is a strong need to extend 
the existing literature by providing a comprehensive assessment of technical frames and value creation that addresses SaaS challenges based on a dynamic perspective. Thus, this study has the following research questions:

- RQ1: How does SaaS firms' perceived SaaS value creation affect their commitment?

- RQ2: How do SaaS firms' technological frames (strength frames and weakness frames) affect their evaluation?

This study integrates sensemaking into the dedication-constraint framework to explain how SaaS firms' perceived value from the firm-vendor relationship transforms their SaaS sensemaking into commitment. The underlying premise of our work is that SaaS firms' commitment depends on whether the SaaS has the features to enhance value based on their SaaS use. Technological frames are used to explain how a firm's perceived SaaS features that reflect the antecedents for SaaS firms' decision for SaaS adoption affect its subsequent perceived value, in terms of benefits and cost for discontinuance, and commitment. We draw on the dedication-constraint framework to explain how the sensemaking of SaaS features affects a firm resource management for value creation, which serves as the motivational impetus to transform the antecedents of decision making into commitment. Value creation from SaaS use draws on the relational view that characterizes perceived benefits as process and knowledge management, and cost for discontinuance (or sunk cost) as process specificity and trust. This study contributes to the research on post-adoption behavior in the SaaS context by accounting for the influence of perceived SaaS features and perceived value created through SaaS resource management on post-adoption phenomena.

\section{Literature Review}

Literature has considered post-adoption use (e.g., commitment) as one of the most important measures of success for IS innovation and outsourcing (e.g., traditional outsourcing, SaaS). Relational marketing literature views commitment as a comprehensive measurement of successful user-provider relationship establishment. Studies have used commitment to represent innovation success at the post-adoption stage, in terms of deepening the user-provider relationship after the consumption of innovative service [7]. Following this set of research, we define commitment as a firm's positive effect on the firm-vendor relationship and willingness to continue it, and both invest in it and foster SaaS-based innovation. Without the minimum level of commitment, SaaS adoption has been deemed a failure. Understanding the formation of commitment is important because it helps vendors understand and develop innovative products, expand the market, and enhance opportunities for better customer service. Besides, commitment also enables client firms to grow beyond their SaaS adoption to post-adoption use that maximizes SaaS value and reduces the cost for switching to a new vendor, including termination cost and redeployment cost.

Prior work on IS-based innovation and value creation from outsourcing has used social-technical theories to explain the formation of commitment. This stream of work invokes individual and relationship-specific factors to explain commitment. Prior studies Kim and Son [8] draw on the dedication-constraint framework to explain how value created by user-provider relationship affects post-adoption behavior in the online service context. They emphasize the role of dedication factors (e.g., perceived benefits, perceived usefulness) and constraint factors (relationship-specific investments, switching costs, a locked-in phenomenon) in explaining why these two types of factors serve as the motivational impetus to transform users' antecedents of decisions to adopt into post-adoption use. Mishar and Agarwal [9] draw on the technological frame theory to explain the influence of organizational sensemaking (conceptualized as managers' perceived IS features such as strength frames and weakness frames) on subsequent use. Studies on SaaS focus on what types of SaaS features (characterized as clients perceived service quality) affect clients' perceived value creation (e.g., perceived usefulness, satisfaction), which in turn influences continuance [10]. Studies on IS innovation and outsourcing identify the factors related to relationship-specific value creation, including relationship-specific investments (e.g., IS specificity, process specificity), a combination of complementary resources (e.g., flexibility in adjusting and aligning processes, task-knowledge coordination), and trust in the governance of opportunism [11].

This stream of work uses stage models to explain IS innovation phenomena, including the adoption decision stage and the post-adoption stage such as commitment. Jasperson et al. [12] suggest that the rational task-technology fit model falls short of explaining post-adoption behavior because it fails to consider the impact of a user's history of 
interacting with the IS application. This argument suggests that the antecedents for IS adoption is not stable. Thus, a dynamic perspective should be used to explain post-adoption phenomena [13]. This implies that users' post-adoption behavior is value-directed (or changed), which reflects that their perceived value based on their interaction with IS applications serves as the motivational impetus to transform their antecedents for adoption decisions into post adoption behavior [14]. While useful, this body of work does not account for a set of SaaS features and "how" and "why" they affect commitment. The relational value created from outsourcing and SaaS has been recognized as a key driver for commitment. However, prior work that provides a comprehensive assessment of what SaaS features for affecting adoption decisions, and how and why relational value determining subsequent commitment remains absent [15]. To fill these gaps and respond to Jasperson et al [12] call, this study aims to investigate the formation of commitment based on a dynamic perspective that emphasizes a client firm's perceived value to transform antecedents for adoption decision into commitment.

\section{Method}

The focal outcome of interest, grounded in the SaaS use, is the extent of a client firm's positive affect toward the firm-vendor relationship, and input to and confidence on the relationship. Consistent with the extant conceptualization of post-adoption behavior, our dependent variable is commitment. We theorize that it is driven by the value created through SaaS consumption, which in turn is influenced by a firm's perceived SaaS features. Figure 1 shows the research model.

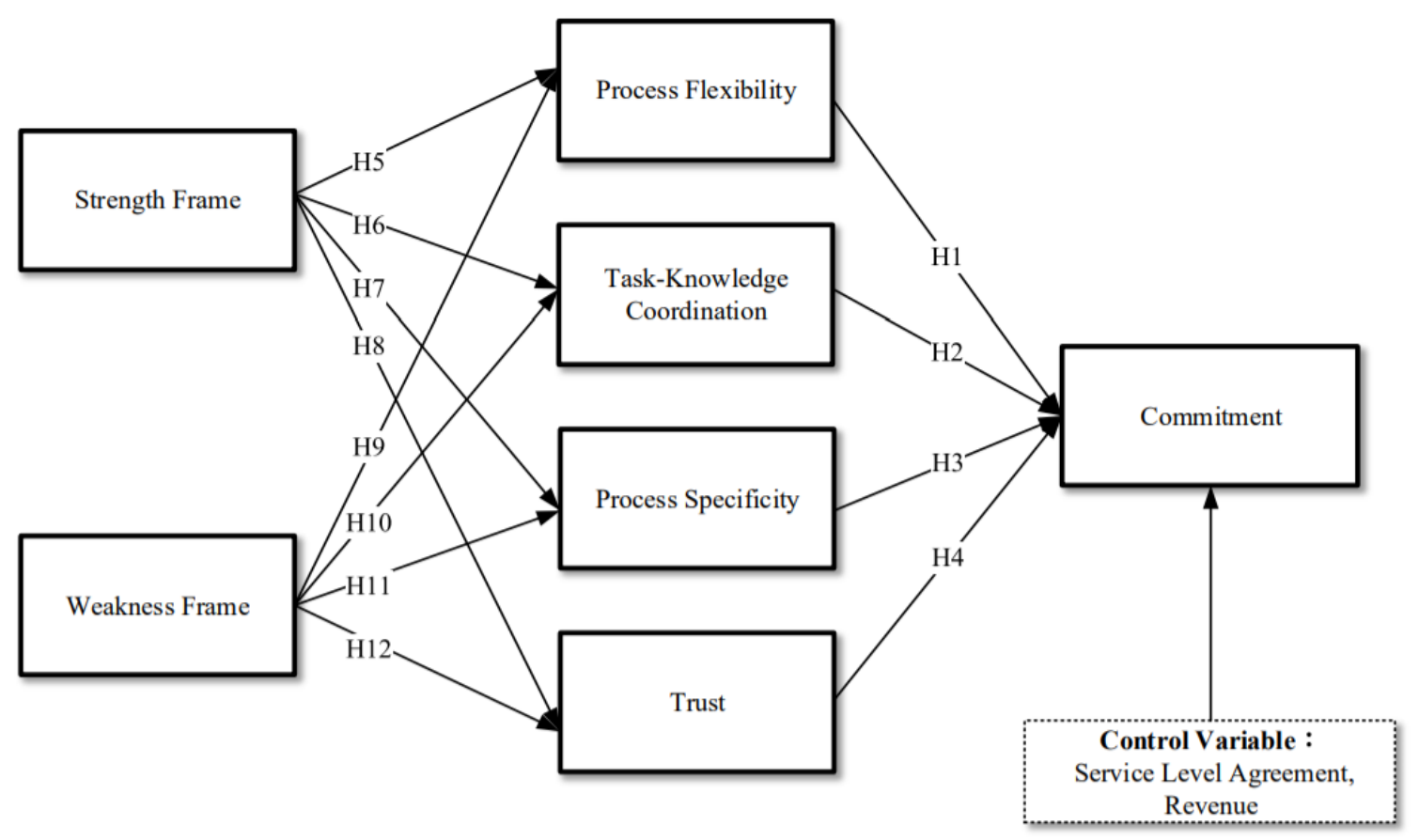

Fig. 1. Research Model

\subsection{Hypotheses between perceived value and commitment}

Studies on online relationship management and user behavior have used the dedication constraint framework to characterize post-adoption behavior. This framework is an appropriate theoretical base for explaining the formation of SaaS commitment because one's dynamic response to SaaS use for motivating commitment is captured by the dual consideration of benefits and investment [16]. However, we extend this framework by combining it with the relational view theory to provide a comprehensive explanation of commitment formation in the SaaS context.

In extending this framework, we hypothesize that SaaS client firms' commitment is determined by four distinctive, yet interrelated, dimensions of value creation process flexibility, task-knowledge coordination, process specificity, and trust. The first two dimensions are the manifestation of the dedication mechanism, and process specificity and trust as the manifestation of the constraint mechanism [17]. 
Following the relational view literature, we theorize process flexibility and task-knowledge coordination as a firm's ability to perform unique combinations of complementary resources from the SaaS vendor. Because firms are inherently different and have different needs for value creation, packaged applications such as ERP, usually do not perfectly match the firm's specific process, data, and needs [18]. Thus, client firms are required to perform the needed adjustment and adaptation to better fit the packaged applications. The aim of process flexibility is to increase fit through the adjustment of internal processes between departments, while task-knowledge coordination enhances the fit through a firm's absorption and application of vendor's best practices to internalize them into the firm's task environment.

Prior work on resource management has manifested value creation through process management (e.g., flexible IT planning processes) and knowledge management (e.g., absorption and application of new IT knowledge), which in turn improve the firm's performance [19]. ERP studies found that a firm's understanding about, assimilation of, and applying the vendor's best practices to the task represents a key source for value creation. This in turn helps the firm gain benefits from ERP use. Business-to-business (B2B) studies emphasize value creation through process flexibility, in terms of adjustment of an internal process to integrate a partner's process, and knowledge management, in terms of acquiring insights and know-how from partners. Overall, this stream of work reports that once a firm can perform good process management and knowledge management through unique combinations of complementary relation-specific resources, it tends to form favorable attitudes and perceptions toward the relationship with the partner (or vendor).

In the SaaS context, the level of a client firm's perceived benefits depends on its process flexibility to solve the problems associated with misfit between the SaaS vendor's service and IS applications. Similarly, task-knowledge coordination enables a firm to gain benefits from its absorption and application of the vendor's best practices to match the SaaS service (e.g., embedded best practice) for better performance [20]. They represent two aspects of benefits gained from relational value. From a dedication perspective, benefits lead to a client firm's favorable attitude, perceptions, and willingness to improve the current relationship through input to it--commitment. Thus, we hypothesize that both process flexibility and task-knowledge coordination exert a positive influence on commitment. We propose $\mathrm{H} 1$ and $\mathrm{H} 2$.

H1. Process flexibility positively affects commitment.

H2. Task-knowledge coordination positively affects commitment.

The relational view suggests that investment in relationship-specific assets represents a key source for value creation, including site-specificity, physical asset specificity, and human asset specificity. In this study, process specificity reflects a client firm's investment on the SaaS applications through adjustments of its business processes and assets (e.g., equipment, human assets) that improve the fit of SaaS use [21]. SaaS studies have recognized the role of process specificity in value creation due to the client firm's effort and investment in customizing the SaaS application to the firm's own routines and enabling new routines. These new routines can better fit the SaaS applications that leverage the SaaS best practices to improve performance. Winkler \& Brown [22] also note that process specificity influences a firm's subsequent SaaS use.

From a constraint perspective, process specificity creates a locked-in phenomenon, because a client's investment in SaaS customization is not easily adapted to a new SaaS application [23]. Thus, investments in SaaS use through process specificity both reduce a client firm's willingness to switch to a new SaaS vendor and motivate the firm's input to maintain the current relationship. Prior work of online service provides evidence that value creation and one's investments serve as a key driver for commitment and postadoption perception and behavior. Thus, we posit that process specificity exerts a positive impact on commitment.

H3: Process specificity positively affects commitment.

The relational view notes that effective governance reduces both the transaction costs and the uncertainty associated with opportunism. They categorize governance mechanisms as formal mechanisms (e.g., third-party enforcement of agreements) and informal mechanisms (e.g., goodwill trust). This study focuses on the latter and defines trust as the belief that the client will trust the vendor to fulfill the client's expectations without taking advantage of the client's 
vulnerabilities [24]. The development of a client firm's trust toward the vendor reflects that the uncertainty in SaaS use is removed and the firm's expectation is matched, resulting in the firm's perceived value creation from SaaS use. IS literature of e-service use and outsourcing shows that trust motivates one's user behavior and positively influences commitment to the service provider.

The development of trust toward the vendor represents the firm's investment in the development of the firm-vendor relationship because this development requires a firm's time and effort to gain a deep understanding of how and whether the vendor's service delivery can meet the firm's needs. This understanding cannot apply to other vendors. Thus, from a constraint perspective, trust development is a manifestation of nontransferable investment and creates a locked-in phenomenon that reduces the firm's willingness to switch to a new SaaS vendor and increases commitment because of the high cost associated with discontinuance. Thus, propose $\mathrm{H} 4$.

H4. Trust positively affects commitment.

\subsection{Hypotheses between perceived value and technological frames}

We draw on the technological frame theory to explain the impact of a client firm's sensemaking of SaaS features on its response to SaaS use. According to this theory, one's technological frames serve as the template for understanding how and whether the use of IS or IT-based innovation can influence a firm's response to the use and perceived value. Positive beliefs derived from technological frames motivate the firm's engagement of IS use and increase the perceived value from it, while negative beliefs discourage its use and reduce the perceived value $[25,13]$.

This study focuses on two types of technological frames, strength frames and weakness frames. Strength frames represent the good fit of SaaS features and have the great potential for value creation from SaaS innovation, while weakness frames reflect the poor fit and the potential for vulnerabilities, uncertainty, and negative consequences from SaaS use.

According to technological frame theory, when firms perceives that SaaS features and use have the potential to improve performance, they are encouraged by this positive perception and belief for more participation in resource management delivered through SaaS, including adjustment, process management, and knowledge management that engender the firms to better leverage SaaS best practices for value creation [26]. This implies that strength frames motivate a client firm's positive response on SaaS use, in terms of more involvement in improving the value of SaaS applications through process flexibility and task knowledge coordination, because of the expectation of benefits gained from SaaS. From a dedication perspective, we expect that strength frames positively affect a client firm's involvement in SaaS use and management of relationship-specific resources, in terms of process flexibility and task-knowledge coordination because of the expected benefits from this involvement. Thus, we propose H5 and H6.

According to technological frame theory, a firm with strength frames tends to view IT-based innovation and features as being worthwhile for investment because strength frames reflect the firm's positive belief on the potential of IT features in helping the firm create value and reduce uncertainty related to innovation [27]. Applying this to the SaaS context, when client firms have positive beliefs on SaaS potential for value creation, they are willing to increase investment and specificity because the specificity reduces the uncertainty in SaaS and maximizes the potential for value creation.

In this study, process specificity is a manifestation of IS specificity. Process specificity reflects firms' effort and investment on increasing the specificity of internal processes that better use SaaS features. From the strategic management perspective, firms' strength frames encourage them to view the SaaS-based innovation as strategic assets and to make a specialized investment on the SaaS due to the expected value creation from SaaS use and reduced uncertainty. This implies that once SaaS firms have strength frames, they have confidence on value creation from SaaS use and are willing to increase process specificity for better leveraging the SaaS applications. Thus, we propose $\mathrm{H} 7$.

As suggested by technological frames, firms' perceived strengths regarding IT innovation serve as the template for interpretation of the potential value creation and reduced uncertainty. This positive perception and interpretation in turn cause the firm to believe that IT and IT providers can meet the firm's expectation and achieve tasks in a reliable way. In the SaaS context, a firm's strength frames reflect its positive interpretation on SaaS features that fit its 
requirements and require less adaptation for leveraging SaaS-based innovation. This implies that the firm is more likely to develop trust in the SaaS provider because less effort and governance are needed for customization and extension, and the firm has more confidence on the SaaS features in completing its task reliably. Thus, we propose H8.

H5. Strength frames positively affect process flexibility.

H6. Strength frames positively affect task-knowledge coordination.

H7. Strength frames positively affect process specificity.

H8. Strength frames positively affect trust.

Contrary to the impact of strength frames on one's perception, firms' weakness frames reflect their negative interpretation on IT-based innovation, including vulnerabilities, uncertainty, and losses as the result of using the innovation. In our context, the weakness frames evaluate the extent to which client firms believe that the use of SaaS applications has a low possibility of value creation [28]. Weakness frames in SaaS reflect the degree of client firms' misfit with vendor's service, which creates uncertainty associated with potential losses and risks, and induces efforts on adjustments and adaption to the SaaS services for value creation. When a firm has weakness frames, it has a negative interpretation on the perceived value through leveraging SaaS features and resource management. Examples include uncertainty and difficulties to make good use of SaaS features due to poor fit between these features and client firms' process, data, and requirements. These negative beliefs in turn discourage the firms' participation in resource management in the SaaS context, including flexibility in the adjustment of internal processes to adapt to the SaaS applications due to the expected difficulties caused by weakness frames and misfit. From a dedication perspective, client firms' negative beliefs reduce their expectation for reaping benefits from SaaS use, which discourages their involvement in resource management to leverage SaaS features. Process flexibility is a manifestation of perceived benefits from resource management, in terms of unique combinations of complementary resources to match the client firm's requirements. Thus, we posit that weakness frames reduce the client firm's perceived value from process flexibility, leading to $\mathrm{H} 9$.

Similar to H9, task-knowledge coordination is a manifestation of dedication factors through unique combinations of complementary resources with the focus on the knowledge management such as absorption and application of SaaS features. From a dedication perspective, weakness frames and negative beliefs on SaaS features reduce a client firm's expected benefits from SaaS use. This in turn implies that weakness frames discourage client firms' participation in leveraging SaaS features through task knowledge coordination, and reduce their expected value from the coordination. Thus, we propose H10.

Building on technological frames, firms' weakness frames reflect their negative expectation of recovering investment on process specificity. This is because process specificity in the poor SaaS fit context (i.e., the poor match between SaaS features and the firm's process and requirements) is less likely to increase value through the redeployment of SaaS features in the firm. Besides, investment on the current SaaS is not worthwhile and exaggerates the uncertainty and risk associated with innovation, which result in the low expected value from process specificity. Thus, we hypothesize that weakness frames reduce client firms' motivation for process specificity. We thus propose H11. When client firms have weakness frames, their negative beliefs on SaaS features cause them to believe that these features are less likely to both satisfy their needs and fulfill tasks reliably. Besides, the uncertainty caused by SaaS outsourcing (e.g., strategic risks, security risks) and SaaS-based innovation becomes exaggerated because of the negative beliefs and bad match between SaaS features and client firms' requirements. This implies that weakness frames cause the development of trust on SaaS difficult. Thus, we propose H12.

H9: Weakness frames negatively affect process flexibility.

H10: Weakness frames negatively affect task-knowledge coordination.

H11: Weakness frames negatively affect process specificity.

H12: Weakness frames negatively affect trust. 


\subsection{Control variables}

The aim of the control variable is to rule out the possibility that empirical results were due to covariance with other variables. In line with prior research on SaaS and outsourcing, we used service level agreement and revenue as the control variables. Service level agreement refers to a formal written contractual agreement between the client and the $\mathrm{SaaS}$ vendor that specifies the various outsourcing features to meet business objectives.

\section{Results and Discussion}

This study seeks to understand how and why managers perceive SaaS features affect commitment through value creation from SaaS consumption. Nine of the twelve proposed hypotheses are supported, which provides ample evidence to reinforce many of our theoretical arguments. The results are summarized in Figure 2.

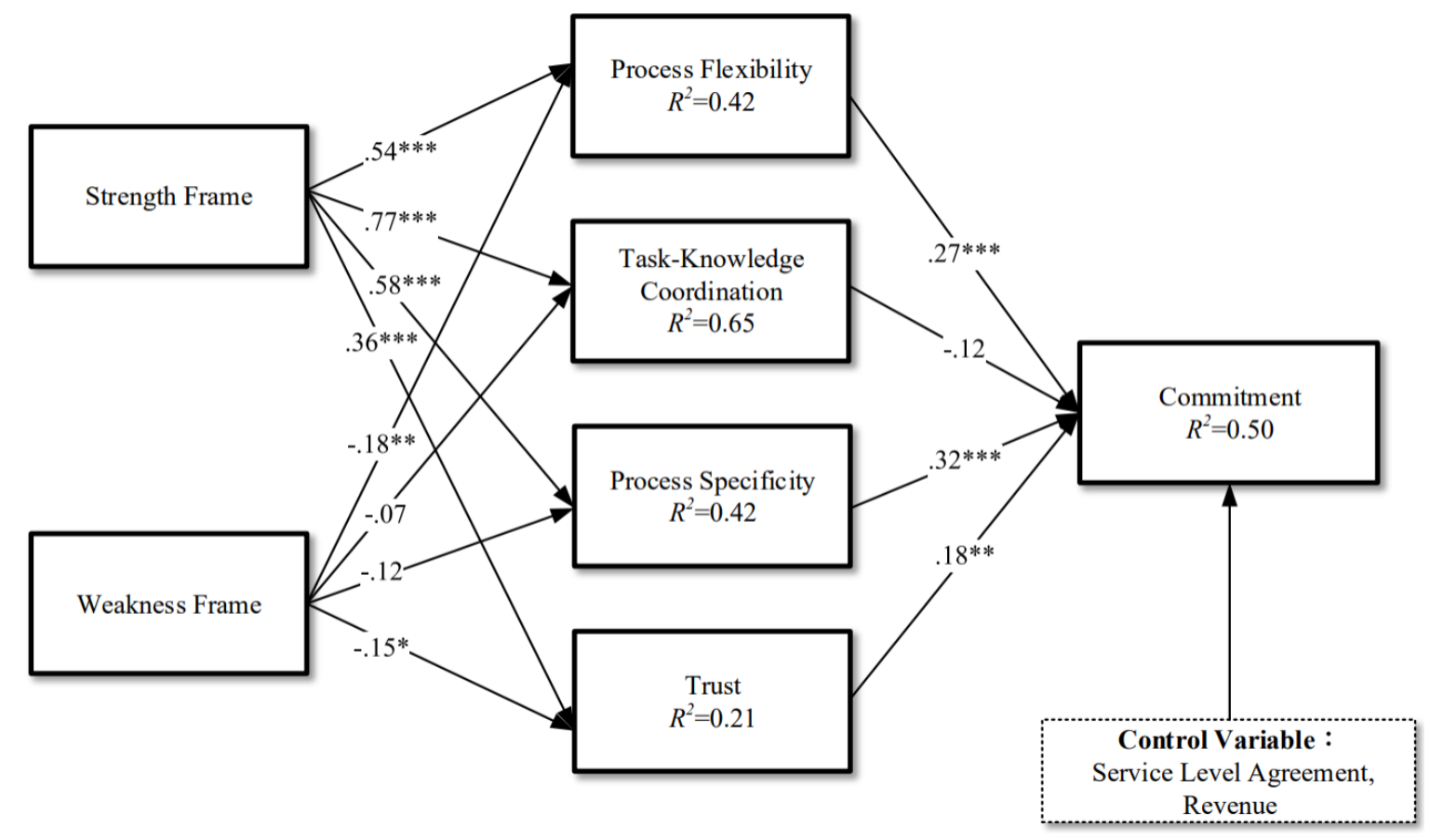

Fig. 2. Results of PLS analysis

First, results regarding the influence of perceived value on commitment show that process specificity is the strongest predictor of commitment (H3) followed by process flexibility as a significant but weaker predictor (H1). Besides, trust plays a significant role in affecting commitment (H4). These results confirm that the dedication-constraint framework is suitable to explain why SaaS client firms' post-adoption behavior is shaped by both dedication factors (H1) and constraint factors (H3, H4). These findings also deepen our understanding on how a firm leverages relationship-specific resources to create value and how these resources are measured in the SaaS context to manifest the key variables of the relational view. Our results indicate that given the uncertainty associated with SaaS features (e.g., multi-tenant architecture, security risks) and SaaS-based innovation, client firms' commitment requires both their genuine appreciation of SaaS (dedication) and not easily transferable investments (constraint), which are captured by the firms' flexibility for process adjustment, investment on processes specificity, and the development of trust.

The influence of task-knowledge coordination on commitment (H2) is not significant. The good reason is that compared to process flexibility that requires the adjustment of internal processes, task-knowledge coordination that entails absorption and application of knowledge regarding SaaS applications faces more difficulties. This is because process adjustment reflects the explicit aspect of leveraging SaaS, while absorption and coordination of knowledge represent the tacit aspect, which requires more interaction with the SaaS vendor and the joint learning between them that are usually infeasible in the SaaS context. 
Second, regarding the influence of technological frames on perceived value, all of the hypotheses associated with strength frames are supported (H5-H8), while the results related to weakness frames are mixed. Prior work on B2B has emphasized the role of IT features (e.g., the flexibility of IT features to integrate partners' applications) in facilitating resource management (knowledge sharing, process integration) and value creation. These findings together with ours, identify the influence of SaaS features on perceived value creation from resource management, implying that the relationship between them is theoretically and empirically sound and can be applied to different contexts, including online and on-demand service for innovation such as SaaS.

The supported hypotheses show that weakness frames exert significant influence on process flexibility (H9) and trust (H12), indicating that client firms' concerns for misfit discourage their involvement in process adjustment and decrease their confidence on the SaaS that can complete tasks in a reliable way. The compelling reason for the unsupported hypotheses (H10, task-knowledge coordination, and H11, process specificity) is that most respondents have extensive SaaS experience, which reduces the negative impact of weakness frames on perceived value. Future work may examine the moderating effect of SaaS experience on the relationship between weakness frames and perceived value.

\section{Conclusion}

This study has the following limitations. First, our theoretical model was examined through a cross-sectional survey, which limits understanding on attributes and substantiates affirmative causality. Thus, future work may use process-oriented methods based on the dedication-constraint framework and technological frames to enrich our understanding about commitment at different levels of SaaS experience. Second, while cases in Taiwan present a great opportunity for understanding the relationship between perception on SaaS features, value creation, and SaaS commitment, the generalizability of our model in other countries with different cultures is limited. Third, we used a single-informant approach to collect data from senior IT managers. Thus, the threat of respondent bias and common method biases cannot be completely removed via statistical means. Future work may collect data using a matchpair field survey of SaaS clients and vendors to increase the applicability of our model. Finally, this study did not consider the moderating effect of the complexity of SaaS applications on the relationship between value creation and commitment. Future research may examine the moderating effect of the complexity of SaaS applications, such as standard commodity applications and large-scale enterprise systems (e.g., ERP).

\section{References}

[1] M. Abdellatif, A. Shatnawi, H. Mili, N. Mohac G. ElBoussaidi, G. Hecht, J. Privat, and Y. G. Guéhéneuc, "A taxonomy of service identification approaches for legacy software systems modernization," J. Syst. Softw., vol. 173, no. 6, pp. 110-131, 2021, doi: 10.1016/j.jss.2020.110868.

[2] M. Kohtamäki, R. Rabetino, S. Einola, V. Parida, and P. Patel, "Unfolding the digital servitization path from products to product-service-software systems: Practicing change through intentional narratives," J. Bus. Res., vol. 137, no. 4, pp. 379-392, 2021, doi: 10.1016/j.jbusres.2021.08.027.

[3] S. Wu, H. Cao, H. Zhao, Y. Hu, L. Yang, H. Yin, and H. Zhu., "A softwarized resource allocation framework for security and location guaranteed services in B5G networks," Comput. Commun., vol. 178, no. 3, pp. 26-36, 2021, doi: 10.1016/j.comcom.2021.07.007.

[4] T. Huikkola, M. Kohtamäki, R. Rabetino, H. Makkonen, and P. Holtkamp, "Overcoming the challenges of smart solution development: Co-alignment of processes, routines, and practices to manage product, service, and software integration," Technovation, vol. 4, no. 1, pp. 34-55, 2021, doi: 10.1016/j.technovation.2021.102382.

[5] S. Khan, S. Iqbal, K. N. Qureshi, K. Z. Ghafoor, P. Kim, and G. Jeon, "Survivability of mobile and wireless communication networks by using service oriented Software Defined Network based Heterogeneous Inter-Domain Handoff system," Comput. Commun., vol. 175, no. May, pp. 177-185, 2021, doi: 10.1016/j.comcom.2021.05.010. 
[6] A. M. Ghouri, V. Mani, Z. Jiao, V. G. Venkatesh, Y. Shi, and S. S. Kamble, "An empirical study of real-time information-receiving using industry 4.0 technologies in downstream operations," Technol. Forecast. Soc. Change, vol. 165, no. 6, pp. 120-141, 2021, doi: 10.1016/j.techfore.2020.120551.

[7] Y. Liang, G. Qi, X. Zhang, and G. Li, "The effects of e-Government cloud assimilation on public value creation: An empirical study of China," Gov. Inf. Q., vol. 36, no. 4, pp. 101-122, 2019, doi: 10.1016/j.giq.2019.101397.

[8] S. S. Kim and J. Y. Son, "Out of dedication or constraint? A dual model of post-adoption phenomena and its empirical test in the context of online services," MIS Q. Manag. Inf. Syst., vol. 33, no. 1, pp. 49-70, 2009, doi: $10.2307 / 20650278$.

[9] A. N. Mishra and R. Agarwal, "Technological frames, organizational capabilities, and IT use: An empirical investigation of electronic procurement," Inf. Syst. Res., vol. 21, no. 2, pp. 249-270, 2010, doi: $10.1287 /$ isre.1080.0220.

[10]R. Rasna, "Comparison of Security Signing Data Authentication Integrity in Combination of Digest And AES Message Algorithm," IJIIS Int. J. Informatics Inf. Syst., vol. 4, no. 1, pp. 1-12, 2021, doi: 10.47738/ijiis.v4i1.72.

[11] N. K. Vien, "Modelling The Relationship of Perceived Quality, Destination Image, And Tourist Satisfaction at The Destination Level,” Int. J. Appl. Inf. Manag., vol. 1, no. 4, pp. 165-172, 2021, doi: 10.47738/ijaim.v1i4.18.

[12] J. Jasperson, P. E. Carter, and R. W. Zmud, "A comprehensive conceptualization of post-adoptive behaviors associated with information technology enabled work systems," MIS Q. Manag. Inf. Syst., vol. 29, no. 3, pp. 525-557, 2005, doi: 10.2307/25148694.

[13] Y. N. Chi, "Modeling and Forecasting Long-Term Records of Mean Sea Level at Grand Isle, Louisiana: SARIMA, NARNN, and Mixed SARIMA-NARNN Models," J. Appl. Data Sci., vol. 2, no. 2, pp. 1-13, 2021, doi: $10.47738 /$ jads.v2i2.27.

[14]D. Cotroneo, A. Paudice, and A. Pecchia, "Automated root cause identification of security alerts: Evaluation in a SaaS Cloud,” Futur. Gener. Comput. Syst., vol. 56, no. 6, pp. 375-387, 2016, doi: 10.1016/j.future.2015.09.009.

[15]A. Saltan and K. Smolander, "Bridging the state-of-the-art and the state-of-the-practice of SaaS pricing: A multivocal literature review," Inf. Softw. Technol., vol. 133, no. June 2020, pp. 106-121, 2021, doi: 10.1016/j.infsof.2021.106510.

[16]R. Pietrantuono, P. Popov, and S. Russo, "Reliability assessment of service-based software under operational profile uncertainty,” Reliab. Eng. Syst. Saf., vol. 204, no. 3, pp. 107-122, 2020, doi: 10.1016/j.ress.2020.107193.

[17] A. M. Ghouri and V. Mani, "Role of real-time information-sharing through SaaS: An industry 4.0 perspective," Int. J. Inf. Manage., vol. 49, no. May, pp. 301-315, 2019, doi: 10.1016/j.ijinfomgt.2019.05.026.

[18] V. H. Torricelli and S. Júnior, "Environmental risk analysis (ERA) in the strategic asset allocation (SAA) of the international reserves (IRs) managed by central banks (CBs)," Lat. Am. J. Cent. Bank., vol. 2, no. 1, pp. 100-121, 2021, doi: 10.1016/j.latcb.2021.100021.

[19]A. F. Mohammad, J. Dargham, H. Mcheick, and A. T. Noor, "Software Evolution as SaaS: Evolution of Intelligent Design in Cloud," Procedia Comput. Sci., vol. 19, no. 3973, pp. 486-493, 2013, doi: 10.1016/j.procs.2013.06.065.

[20] Y. Wang, S. H. Hsiao, Z. Yang, and N. Hajli, "The impact of sellers' social influence on the co-creation of innovation with customers and brand awareness in online communities," Ind. Mark. Manag., vol. 54, no. 3, pp. 56-70, 2016, doi: 10.1016/j.indmarman.2015.12.008.

[21] T. Matsuda, "Research on New Regional Creation Business Model Utilizing Social Network and Crowdfunding," Int. J. Appl. Inf. Manag., vol. 2, no. 1, pp. 1-12, 2022.

[22]T. J. Winkler and C. V. Brown, "Horizontal allocation of decision rights for on-premise applications and software-as-a-service,” J. Manag. Inf. Syst., vol. 30, no. 3, pp. 13-48, 2013, doi: 10.2753/MIS0742-1222300302.

[23] M. Yassin, C. Talhi, and H. Boucheneb, "ITADP: An inter-tenant attack detection and prevention framework for multi-tenant SaaS,” J. Inf. Secur. Appl., vol. 49, no. 4, pp. 102-115, 2019, doi: 10.1016/j.jisa.2019.102395. 
[24] M. Makki, D. Van Landuyt, B. Lagaisse, and W. Joosen, "Thread-level resource consumption control of tenant custom code in a shared JVM for multi-tenant SaaS,” Futur. Gener. Comput. Syst., vol. 115, no. 4, pp. 351-364, 2021, doi: 10.1016/j.future.2020.09.025.

[25]H. Fan, F. K. Hussain, M. Younas, and O. K. Hussain, "An integrated personalization framework for SaaS-based cloud services," Futur. Gener. Comput. Syst., vol. 53, no. 3, pp. 157-173, 2015, doi: 10.1016/j.future.2015.05.011.

[26]O. Seong Tak and S. Park, "Investigating SaaS Providers' market success based on the Multivariate LGCM Approach," Procedia Comput. Sci., vol. 139, no. 7, pp. 227-235, 2018, doi: 10.1016/j.procs.2018.10.255.

[27]A. Mitra, N. O'Regan, and D. Sarpong, "Cloud resource adaptation: A resource based perspective on value creation for corporate growth," Technol. Forecast. Soc. Change, vol. 130, no. 3, pp. 28-38, 2018, doi: 10.1016/j.techfore.2017.08.012.

[28] S. S. T. Reddy and G. K. Shyam, "A machine learning based attack detection and mitigation using a secure SaaS framework,” J. King Saud Univ. - Comput. Inf. Sci., vol. 12, no. 3, 2020, doi: 10.1016/j.jksuci.2020.10.005. 